\title{
VOZES E DISCURSOS NO \\ PROGRAMA DE EDUCAÇÃO AMBIENTAL DA ITAIPU BINACIONAL (PR): BREVE ENSAIO
}

\author{
Patrícia Garcia da Silva Carvalho ${ }^{1}$ \\ Adriana Monteiro da Costa² \\ Cristiana Rocker ${ }^{3}$
}

Resumo: O Programa Cultivando Água Boa (CAB) da Itaipu Binacional desenvolvido na Bacia do Paraná 3 (BP3) configurou a Educação Ambiental como programa integrador dos 20 programas que compuseram as intervenções socioambientais no território. Analisar a comunicação corporativa no que tange ao Programa de Educação Ambiental da Itaipu Binacional a partir de um recorte temporal e documental perfaz o objetivo deste artigo. Para tanto, buscaram-se o Jornal do $C A B$ e bibliografia como corpus da análise do discurso. O Jornal do CAB cumpre o papel de divulgar as ações e resultados do programa, além de dar visibilidade aos parceiros e aos esforços de articulação social e política na BP3.

Palavras-chave: Cultivando Água Boa; Bacia do Paraná 3; Gestão Participativa.

Abstract: The Itaipu Binacional Program Cultivando Água Boa (CAB) was developed at Paraná Basin 3 (BP3) and configured Environmental Education as an integral framework for the 20 programs that made up the socioenvironmental interventions in the territory. This article presents an analysis of the corporate communication of the Itaipu Educational's Program from a time and documentary perspective. Analyses were based on a review of the literature and the $C A B$ journals. The CAB journal fulfills the role of disseminating the actions and results of the program, in addition to giving visibility to the partners and the efforts of social articulation and politics at BP3.

Keywords: Cultivating Good Water; Paraná River 3; Participative Management.

\footnotetext{
${ }^{1}$ Universidade Federal de Minas Gerais. E-mail: patricia.nativasocioambiental@gmail.com. Link para o Lattes: http://lattes.cnpq.br/5353302144278234

${ }^{2}$ Universidade Federal de Minas Gerais. E-mail: drimonteiroc@yahoo.com.br. Link para o Lattes: http://lattes.cnpq.br/1744325625181595

${ }^{3}$ E-mail: cris rocker@yahoo.com.br. Link para o Lattes: http://lattes.cnpq.br/0525175858558806
} 


\section{Introdução}

A região Oeste do Paraná, no período do governo militar, foi palco de uma intervenção que alterou a paisagem natural, social, econômica e cultural com a implantação da Usina Hidrelétrica da Itaipu Binacional. O governo de Juscelino Kubitschek, de 1956 a 1961, foi marcado pelo lema "Cinquenta anos em cinco" e, vislumbrando a necessidade de ampliar a oferta de energia voltada para os objetivos do desenvolvimento do país, o então presidente desencadeou estudos de aproveitamento hidrelétrico do rio Paraná, na região de Guaíra.

Sob a tutela do regime militar em 1966, foi assinada a Ata do Iguaçu pelos presidentes do Paraguai (Stroessner) e do Brasil (Castelo Branco) (AMARAL, 2018, p.97). Naquele momento, o crescimento econômico e o desenvolvimento do país foram diretamente associados à implantação da Hidrelétrica de Itaipu. Os recursos para a implementação da usina foram repassados pelos Banco Internacional para Reconstrução e Desenvolvimento (Banco Mundial), Banco Interamericano de Desenvolvimento (BID) e Fundo Monetário Internacional (FMI). Com a construção de Brasília e as grandes obras da década de 70 e 80 (hidrelétricas e transamazônica), o país entra na fase do endividamento e do monitoramento econômico e financeiro pelos bancos internacionais.

Nesse contexto, a hidrelétrica de Itaipu Binacional promove uma diversidade de impactos negativos de ordem social, cultural, ecológica, paisagística, biológica, física e econômica de grande significância e relevância (rupturas de relações sociais, realocamento de populações indígenas, perdas de patrimônios arqueológicos e paleontológicos, perdas de terras agricultáveis, rupturas da cadeia produtiva regional, perdas de patrimônio paisagístico como a Sete Quedas, perda de diversidade biológica de fauna e flora, entre outros). Domínguez e Pimentel (2017, p.5) citam que "aproximadamente 60.000 pessoas que tiveram de deixar suas terras e casas para a implantação da hidrelétrica".

Contudo, os impactos negativos foram claramente desconsiderados pelo governo militar em prol de uma estratégia de crescimento econômico alicerçada na intervenção territorial sem um devido equacionamento e valoração dos impactos ambientais ${ }^{4}$. Observando-se a legislação de avaliação de impactos ambientais e de licenciamento ambiental construídas no final da década de 80 , a usina de Itaipu Binacional não teria prerrogativas para a implantação, a não ser pela intervenção autoritária do Estado nos órgãos de licenciamento e fiscalização.

A obra da Usina de Itaipu Binacional foi iniciada em 1974 e finalizada em 1982, com a formação do reservatório e inundando uma área de $1.350 \mathrm{~km}^{2}$

${ }^{4} \mathrm{O}$ termo ambiental está embasado no conceito de Genebaldo Freire Dias de Ambiente Total e envolve aspectos sociais, culturais, paisagísticos, econômicos, biológicos, físicos, ecológicos, tecnológicos e políticos.

Revbea, São Paulo, v.16, № 1: 45-65, 2021. 
(VIEZZER et al. 2007). Em 1974, o Banco Mundial lançou o documento intitulado Environment, Health, and Humam ecologic considerations in economic development projects, que norteava avaliações de custo-benefício em grandes obras, indicando a adoção de medidas compensatórias para os impactos significativos e irreversíveis.

A empresa binacional definiu a política ambiental em 1975 e, no ano 2000, foi delineado o Plano Diretor de Gestão Ambiental, em substituição ao Plano Diretor de 1982 (CASALE; LINDINO, 2017, p.58). Em 2003 ocorreu uma mudança substancial da missão institucional incorporando-se, além da geração de energia elétrica, a Responsabilidade Socioambiental e a Sustentabilidade. Assim, a empresa passava a assumir de forma clara os passivos ambientais associados à implementação da usina e o papel de agente catalisador do desenvolvimento regional. O Programa Cultivando Água Boa (CAB) surgiu nesse momento de transformação política na gestão do país e da empresa binacional. Para VIEZZER et al. (2007, p.53) "o programa representa um marco histórico [...], resgatando princípios e valores, atuando com a Educação Ambiental reflexiva, crítica, transformadora e emancipatória de consciências esclarecidas".

Diante desse contexto, o presente trabalho, associado ao doutorado em andamento no Instituto de Geociências da Universidade Federal de Minas Gerais (UFMG), tem por objetivo analisar uma das ferramentas de comunicação corporativa no que tange ao Programa de Educação Ambiental da Itaipu Binacional.

\section{Metodologia}

Neste ensaio, o corpus sob observação é a comunicação corporativa da Itaipu Binacional, o Jornal do CAB. As bases teóricas da Análise do Discurso remetem-se a Orlandi - Análise de discurso: princípios e procedimentos (1999); As Formas do Silêncio (1992); Discurso em Análise: Sujeito, Sentido, Ideologia (2012) - e a Pêcheux - Semântica e discurso: uma crítica da afirmação do óbvio (1975).

Orlandi (1999, p.12) chama a atenção para a etimologia da palavra discurso que remete à ideia de percurso, da palavra em movimento, e à prática da linguagem. Assim, através da análise do discurso pode-se compreender a língua fazendo sentido, constituindo o social, o homem e a sua história.

Segundo Pêcheux (1975, p.160), a análise do discurso tem como objeto de estudo o discurso e nesse contexto,

As palavras, expressões, proposições etc., mudam de sentido segundo as posições sustentadas por aqueles que as empregam, o que quer dizer que elas adquirem seu sentido em referência a essas posições, isto é, em referência às formações 
ideológicas [...] nas quais essas posições se inscrevem. Chamaremos, então, formação discursiva aquilo que, numa formação ideológica dada, isto é, a partir de uma posição dada numa conjuntura dada, determinada pelo estado da luta de classes, determina o que pode e deve ser dito (articulado sob a forma de uma arenga, de um sermão, de um panfleto, de uma exposição, de um programa etc.).

A opção pelo Jornal do Cultivando Água Boa associa-se ao fato de ser publicação de responsabilidade da empresa e que busca alcançar diferentes atores sociais na BP3, objetivando-se assim compreender qual o discurso da empresa que interpela os moradores da região e aqueles envolvidos no CAB. Ao mesmo tempo, analisar a inserção da Educação Ambiental nas matérias e entrevistas retratadas no jornal.

O Jornal de 2007 foi selecionado por estar disponível no site da empresa e ser a publicação mais antiga disponibilizada. O ano de 2007 marcou a realização do quarto encontro do Programa $C A B$, que ocorria anualmente com o objetivo de reunir os participantes nas atividades do programa, além de lideranças locais.

Segundo a análise do discurso, a materialidade específica da ideologia é o discurso e a materialidade específica do discurso é a língua. Assim, observa-se e analisa-se a relação língua-discurso-ideologia. Segundo Pêcheux (1975, apud ORLANDI, 1999, p.17), "não há discurso sem sujeito e não há sujeito sem ideologia: o indivíduo é interpelado em sujeito pela ideologia e é assim que a língua faz sentido".

De acordo com Orlandi (1999, p.10),

Toda formação social, no entanto, tem formas de controle da interpretação, que são historicamente determinadas: há modos de se interpretar, não é todo mundo que pode interpretar de acordo com a sua vontade, há especialistas, há um corpo social a quem se delegam poderes de interpretar (logo de "atribuir" sentidos), tais como, o juiz, o professor, o advogado, o padre etc.

Nesse contexto referenciado em Orlandi e Pêcheux, delineiam-se as seguintes questões: quais vozes aparecem no Jornal? a quem se referem? existem atores invisibilizados? os aspectos formativos $e$ as atividades associadas à Educação Ambiental têm espaço no jornal? Essas são as perguntas que direcionam nossa busca de compreensão no corpus definido na pesquisa. 


\section{O Programa de Educação Ambiental e o Programa Cultivando Água Boa - Educação Ambiental Crítica: a vivência no Programa de Educação Ambiental da Itaipu Binacional}

O Programa de Educação Ambiental (PEA) da Itaipu Binacional Margem Esquerda/Brasil integrou o Programa Cultivando Água Boa (CAB) implementado a partir de 2003, na Bacia do Paraná 3 (BP3), área de influência do reservatório da empresa, situada na mesorregião do Oeste do Paraná, com 28 municípios no estado do Paraná e Mundo Novo no estado do Mato Grosso do Sul (Figura 1).
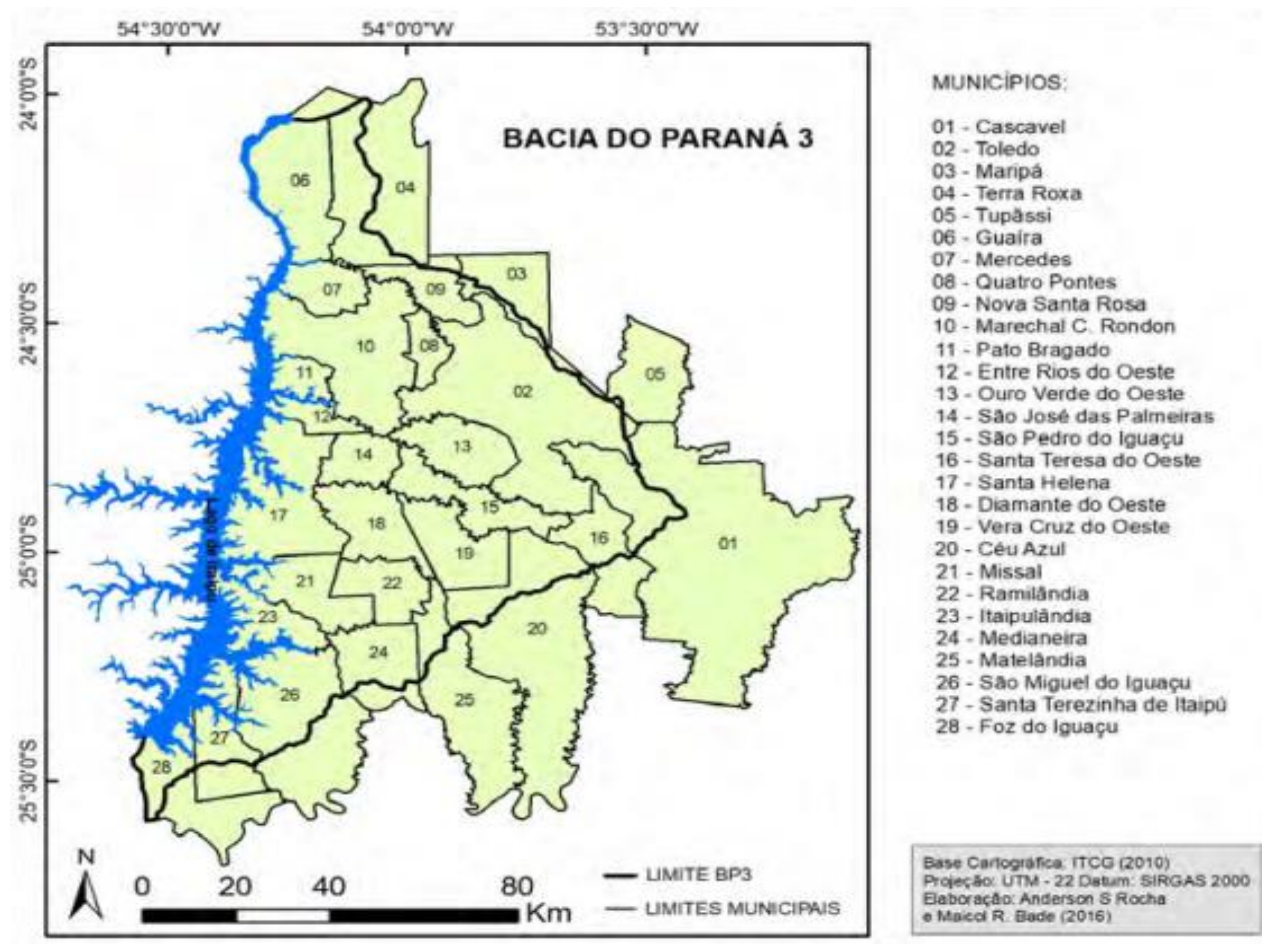

Figura 1: Bacia do Paraná 3. Fonte: ROCHA (2016).

Em 2003, a mudança de gestão da empresa foi traduzida em nova missão institucional que, para além de gerar e distribuir energia elétrica, incorporou os objetivos de Responsabilidade Socioambiental e Sustentabilidade, em um novo modelo de gestão alicerçado na gestão territorial por bacia hidrográfica e na gestão participativa. Conforme destacado no Relatório de Sustentabilidade da Itaipu Binacional, "gerar energia elétrica com qualidade, com responsabilidade social e ambiental, impulsionando o desenvolvimento econômico, turístico e tecnológico sustentável no Brasil e no Paraguai" (ITAIPU, 2007, p.11). O CAB foi concebido para representar esse novo modelo de gestão sustentável da empresa com base na nova missão estabelecida e, assim, orientar ações com foco socioambiental relacionadas à 
conservação dos recursos hídricos, matéria-prima da geração de energia (CASALE; LINDINO, 2017, p.65).

Casale e Lindino (2017) apontam que a primeira mudança atrelada ao CAB foi a ampliação da área de atuação da empresa, a BP3. Inicialmente, a atuação da empresa envolvia 16 municípios que fazem margem ao reservatório, passando a atuar nos 29 municípios que integram a BP3 (VITORASSI et al., 2011). O programa foi estruturado em 20 programas que envolviam 65 projetos interconectados, nos quais a gestão e a operação do programa partem do processo da gestão participativa, viabilizada pelas parcerias formais com instituições públicas, privadas, entidades sociais e ambientais. Comitês Gestores Municipais articulavam diferentes setores da sociedade e parceiros (cerca de 2.000 instituições governamentais e da sociedade civil, incluindo universidades, prefeituras, cooperativas, associações, produtores rurais) (Figura 2).

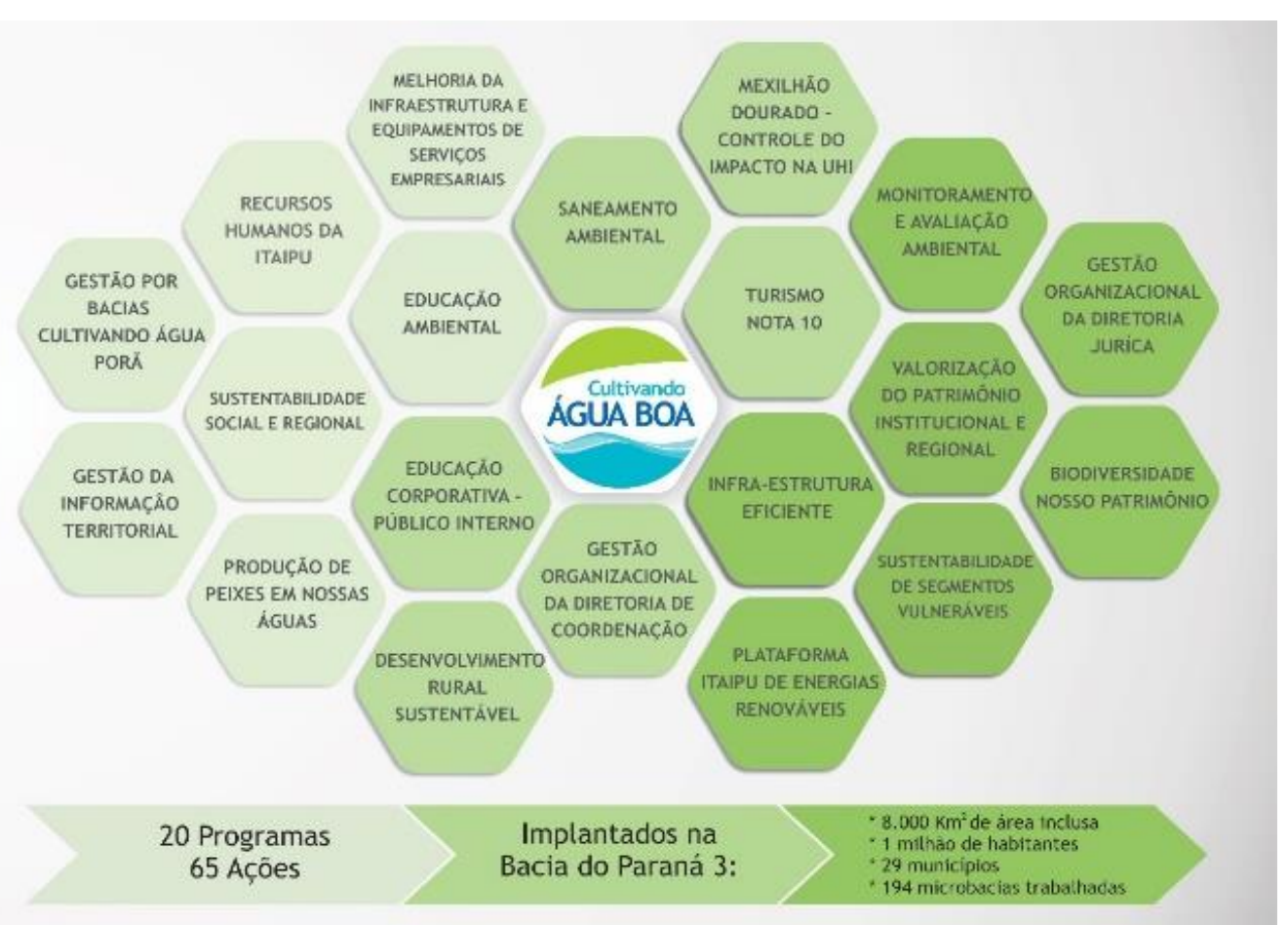

Figura 2: Programa CAB desdobrado em 20 programas.

Fonte: Casale; Lindino (2017).

Importa salientar que "nos comitês não existem relações hierárquicas diretas, mas uma administração horizontalizada que se integra a fim de gerir os programas de desenvolvimento sustentável e recuperação dos passivos ambientais detectados no território" (CASALE; LINDINO, 2017, p.69).

A empresa passa então a assumir papel preponderante no desenvolvimento regional do Oeste do Paraná e, 
adotou para si o papel de indutora de um verdadeiro movimento cultural rumo à sustentabilidade, articulando, compartilhando, somando esforços e dividindo responsabilidades com os diversos atores da Bacia Hidrográfica do Paraná 3 em torno de uma série de programas e projetos interconectados de forma sistêmica e holística, e que compõem o Cultivando Água Boa. Esses objetivos foram criados à luz de documentos planetários como a Carta da Terra, a Agenda 21 e os Objetivos do Milênio (CULTIVANDO ÁGUA BOA, 2017).

A partir da revisão da missão institucional da empresa, a Educação Ambiental que estava inserida no Plano Diretor de Gestão Ambiental de 2000 passou por reformulação e o PEA adotou quatro pilares com o objetivo de organizar as ações no âmbito corporativo, nas estruturas educadoras (Ecomuseu e Refúgio Biológico) e na BP3, conectando os programas do CAB e estabelecendo diálogos e processos formativos integrados (VITORASSI, 2014). Salienta-se que a educomunicação permeava, assim, os outros três pilares da Educação Ambiental.

O PEA foi concebido com base na Política Nacional de Educação Ambiental (PNEA) e no Programa Nacional de Educação Ambiental (ProNEA) e teve sua base teórica desenvolvida em parceria com os idealizadores do ProNEA no âmbito dos Ministérios da Educação e do Meio Ambiente. A diversidade de olhares dos idealizadores do PEA assegurou aspectos fundamentais da ideologia do programa: visão sistêmica da problemática ambiental; reconhecimento de uma crise civilizatória de valores; assunção da necessidade de ação coletiva e de construção de saberes compartilhados; formação apoiada na visão crítica da sociedade de massa e do consumo, no exercício da cidadania, no respeito às diversidades, no empoderamento social e na cultura da paz. Esses aspectos citados seriam a base para a transformação social na região e da melhoria da qualidade de vida.

Importante salientar que em termos pedagógicos a matriz teórica do programa está embasada em Paulo Freire, na Pedagogia da Autonomia, Pedagogia dos Oprimidos, Educação e Mudança, Pedagogia da Esperança, Pedagogia da Indignação, e, sobretudo, Pedagogia da Solidariedade.

O PEA atuava em rede nos 29 municípios, tendo como elo entre a Itaipu Binacional e os municípios o Gestor de Educação Ambiental, sendo este representante da sociedade civil e do poder público municipal. Nesse caso, selecionado pela administração pública (secretário de educação, meio ambiente ou turismo, na maioria das vezes) e tendo sua base no Programa de Formação de Educadores Ambientais (FEA) (CASALE et al., 2014).

A rede de Educação Ambiental foi assim composta pelos educadores ambientais do Programa FEA, pelos coletivos educadores municipais, pelo coletivo jovem, pelos comunicadores comunitários, pelo coletivo de pescadores, pelas ações nas escolas, salas e espaços verdes, através da Ecopedagogia, e pelas ações integradas no programa Cultivando Saúde 
(pessoas envolvidas na área da saúde) e Saberes e Sabores (nutricionistas, merendeiras escolares e produtores da agricultura familiar) (Figura 3).

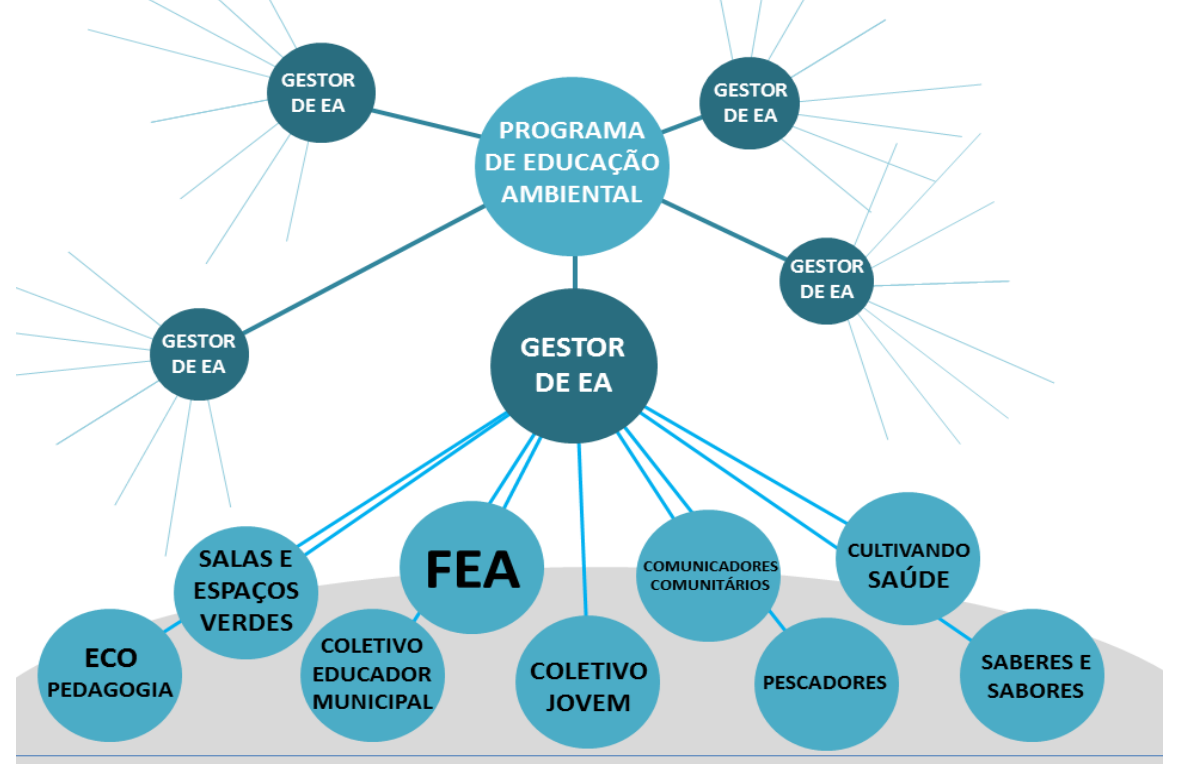

Figura 3: Estrutura do Programa de Educação Ambiental. Fonte: Itaipu Binacional, Nativa Socioambiental (2015).

A formação de educadores ambientais se dava pela Pesquisa-AçãoParticipante, mais conhecida por Pessoas que Aprendem Participando (PAP) (CARVALHO et al., 2013), que participavam de um ciclo de formação de dois anos e que constituíam comunidades de aprendizagem, nas quais eram articulados e desenvolvidos projetos de intervenção socioambiental. No FEA, cada um dos envolvidos no processo de aprendizagem alternavam entre os papéis de aprendiz/educador. Importa destacar que a metodologia da Pesquisa-Ação-Participante promove "a ação educativa e a participação dos envolvidos, produzindo conhecimentos sobre a realidade a ser estudada e, ao mesmo tempo, realiza um processo educativo, participativo, para o enfrentamento dessa mesma realidade" (TOZONI-REIS, 2005, p.271-272).

No FEA, o primeiro nível (PAP 1) era composto pela equipe idealizadora dos Ministérios do Meio Ambiente e da Educação; o PAP 2, pelo Coletivo Educador, que reuniu instituições diversas para promover a articulação institucional e criar condições para o desenvolvimento continuado de ações de formação em Educação Ambiental; o PAP 3, pelos educadores ambientais formados a partir do PAP 2, representando todos os segmentos dos 29 municípios da bacia; e, por fim, o PAP 4, constituído por inúmeras comunidades de aprendizagem que reuniam os atores sociais envolvidos no programa $^{5}$ (Figura 4). mediadora e compôs a equipe gestora do programa, por meio da empresa Nativa Revbea, São Paulo, v.16, № 1: 45-65, 2021. 


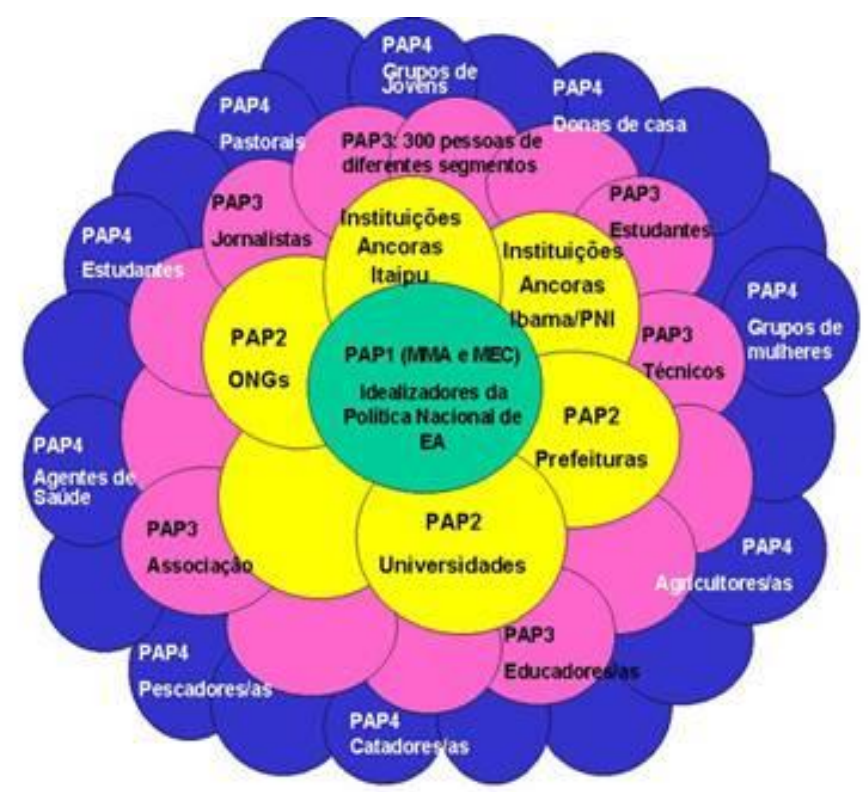

Figura 4: Estrutura do Processo Formativo no FEA.

Fonte: Viezzer et al. (2007).

Assim, o FEA articulava a capilaridade e o enraizamento da Educação Ambiental no território através das comunidades de aprendizagem e dos projetos de intervenção educadora, além de fortalecer os coletivos educadores municipais. Os educadores ambientais, que eram cerca de 300 , em ciclos bianuais participavam das outras ações da rede de EA como facilitadores e mediadores das ações educativas. O cardápio de aprendizagem era definido pelos próprios educadores, a cada final de ano, e envolvia aspectos associados ao desenvolvimento humano, além de temas sociais, econômicos, culturais, educacionais, políticos, tecnológicos, ecológicos, de políticas públicas, gestão ambiental, saúde, dentre outros.

Ao longo de mais de uma década, cerca de 22 mil pessoas participaram das atividades do programa, sendo formados mais de 900 educadores ambientais em ciclos bianuais de formação (2006-2007; 20092010; 2011-2012; 2013-2014; 2015-2016) e constituídas 318 comunidades de aprendizagem que mobilizaram mais de 18.000 PAP4 com papéis diversos na sociedade: catadores, agentes de saúde, integrantes de associação e cooperativas, funcionários de empresas, grupo de mulheres, entidades religiosas, integrantes de projetos sociais, idosos, centros da juventude, moradores de bairro, alunos e professores de todos os níveis de ensino (ROCKER et al., 2017).

No estudo realizado por Klunk et al. (2018, p.22), concluiu-se que a motivação dos educadores que participaram do programa se dava "com 0

Socioambiental, braço executivo da Itaipu Binacional para implementação da Educação Ambiental na BP3. 
compartilhamento de informações e com o acesso ao conhecimento proporcionado pelo programa, a partir dos encontros de formação, e permanece contínua ao longo do desenvolvimento de suas atividades".

No livro intitulado $A$ Educação Ambiental Empresarial: como condição estratégica na empresa (2017), Casale e Lindino apresentam o estudo de caso do PEA. As autoras exploram a relação entre o papel das empresas para além do papel de agentes de mercado e inserem, nesse contexto, a Educação Ambiental como estratégia de promoção de mudanças individuais, coletivas e organizacionais, a partir da formação corporativa e de mudanças na visão, missão e atuação empresariais.

As autoras trabalharam com Análise do Discurso e entrevistaram a alta e média administração vinculada ao Programa CAB. As informações coletadas foram organizadas em seis categorias, quais sejam: ressignificação da Educação Ambiental; Educação Ambiental empresarial; nível de envolvimento no programa de Educação Ambiental; ganho empresarial e organizacional; desafio da implantação; e expectativas. Ao abordarem a Educação Ambiental como estratégia na empresa, as autoras referenciadas em Sauvé (2005) apontam as correntes de longa tradição da Educação Ambiental: naturalista, conservacionista/recursista, resolutiva, sistêmica, científica, humanista e moral/ética.

São listadas, ainda, as correntes recentes: holística, biorregionalista, práxica, crítica social, feminista, etnográfica, ecoeducação e sustentabilidade. Interessante observar que o Professor Luiz Antônio Ferraro Junior, prefaciante do livro, chama a atenção para a eleição das autoras da Itaipu Binacional como estudo de caso, um case que se configura como "um ponto fora da curva nas relações ambiente-empresa e que demostra as possibilidades que surgem quando uma empresa leva realmente a sério seu papel no cuidado com a sociedade, o bem público e o meio ambiente" (CASALE; LINDINO, 2017, p.18).

Essa visão do professor é corroborada por cientistas nacionais e internacionais que relatam a percepção pessoal do programa $C A B$ em entrevistas e documentos publicados pela empresa. As autoras buscaram, assim, identificar através dos discursos dos dirigentes aspectos que contribuíram para a estruturação do programa dentro e fora da empresa, bem como fatores que comprometeram a ampliação das ações do programa.

As análises desenvolvidas por Casale e Lindino (2017) vêm corroborar parte das inquietações que delinearam o escopo deste ensaio. Interessa-nos, simultaneamente, a análise do discurso realizada e a abordagem da Educação Ambiental crítica no âmbito do programa CAB.

Outro aporte bibliográfico importante é a tese de Anelize Queiroz Amaral (2018) intitulada Educação Ambiental e a dimensão política: um estudo de caso do programa de formação de educadores ambientais da usina hidrelétrica Itaipu Binacional, que compartilha a análise do discurso dos educadores ambientais e reflete sobre o silenciamento do contexto histórico e político no qual a hidrelétrica foi implantada e as omissões quanto aos impactos

Revbea, São Paulo, v.16, № 1: 45-65, 2021. 
ambientais deflagrados pela obra no transcorrer do percurso formativo dos educadores ambientais.

Tendo em vista a ideologia do Desenvolvimento Sustentável que alicerçou o programa $\mathrm{CAB}$, busca-se compreender "a maneira como a linguagem está materializada na ideologia e como a ideologia se manifesta na língua" (ORLANDI, 1999, p.16).

\section{Análise do Discurso: Jornal Cultivando Água Boa da Itaipu Binacional - 2007}

O Jornal Cultivando Água Boa, o Programa Socioambiental da Itaipu Binacional, sob análise, data de junho de 2007, apresenta capa e 26 páginas com 56 imagens. Inicialmente, o Jornal foi analisado sob o ponto de vista da autoria - quem discursava - e, para as matérias institucionais, identificaram-se os padrões de reportagem: divulgação dos programas institucionais associados ao $\mathrm{CAB}$ ou divulgação da empresa no âmbito geral; divulgação da Educação Ambiental; textos institucionais dos idealizadores do Programa CAB; textos de técnicos/cientistas da área socioambiental ou de políticos.

Nesse contexto de análise preliminar de conteúdo, o jornal contém: vinte e uma matérias de divulgação das ações do $C A B$; uma de divulgação da Itaipu Binacional; duas de idealizadores do CAB; três de técnicos e cientistas e quatro que enfocam o programa de Educação Ambiental do CAB. Estas quatro últimas matérias abordaram as metodologias $e$ os investimentos em mobilização e formação de pessoas para a atuação no $C A B$, além de darem destaque à participação social através do monitoramento participativo dos rios e da assinatura de novos convênios com organizações com os municípios.

Quanto às 56 imagens/fotos que acompanham as matérias: três são de personalidades públicas; três de paisagens naturais nas quais a água é o elemento dominante; vinte e cinco de autoridades, técnicos e cientistas; e vinte e cinco das comunidades e parceiros locais das ações do CAB na BP3. As figuras públicas são: Maria Betânia, que cantou na abertura do encontro anual do programa; e Marcos Palmeira, ator, conhecido pela vinculação à agricultura orgânica e familiar. Dentre as autoridades, apareceram reitores de universidades, prefeitos, secretários municipais, a alta administração da empresa, ministros e dirigentes de organismos internacionais associados à problemática socioambiental. Dentre os técnicos e cientistas, sobressaem aqueles voltados à gestão dos recursos hídricos. O destaque dado aos políticos e cientistas pode ser apontado como demonstração de força política e respaldo técnico-científico à ação da empresa binacional na BP3.

As fotos dos parceiros locais referem-se aos programas de Desenvolvimento Rural Sustentável (Plantas Medicinais, Agricultura Familiar, Agricultura Orgânica), Educação Ambiental, Monitoramento Participativo das Águas, Coleta Solidária, Merenda Escolar, Sustentabilidade das Comunidades 
Indígenas, Produção de Peixes em Nossas Águas e Pesquisa e Cooperação Interinstitucional.

No sentido de estruturar a análise, buscou-se identificar os termos que se remetem aos objetivos do Programa, os quais foram agrupados em categorias de acordo com afinidade conceitual, e tiveram suas ocorrências contabilizadas ao longo das matérias do jornal. Assim, foram concebidas sete categorias que retratam os princípios do programa e a sua inserção no território. A Tabela 1 apresenta as categorias, termos e número de ocorrências.

1. Integração social: acordo, protocolo, convênio, pactos, cooperação, integração, intercâmbio, parcerias;

2. Formação: educação, Educação Ambiental, capacitação, cursos;

3. Política municipal: prefeitos, secretários;

4. Participação social: participação, comunidades, coletivos;

5. Desenvolvimento sustentável: sustentabilidade;

6. Pesquisa: desenvolvimento científico e tecnológico;

7. Gestão de Bacias Hidrográficas: água, recursos hídricos, rios/córregos, bacias, microbacias, BP3.

A categoria integração social refere-se à articulação política e institucional que viabiliza, nos níveis municipal, estadual, federal e internacional, as ações do $C A B$ junto às prefeituras municipais, órgãos governamentais, parceiros da iniciativa privada e organismos internacionais vinculados à pesquisa, educação e políticas públicas. A categoria formação engloba atividades formativas, cursos, capacitações, ações de educação formal e as ações do PEA. As atividades formativas estão associadas aos diferentes programas do $C A B$ e, nesse número do jornal, são divulgadas as ações formativas com as comunidades indígenas, pescadores, agricultores, agentes de saúde, comunidades, pecuaristas, merendeiras e nutricionistas e educadores ambientais vinculados ao PEA. Na categoria política municipal foram inseridas as referências aos prefeitos e secretários municipais dos 29 municípios incorporados ao programa. Destacaram-se as secretarias de meio ambiente, educação, saúde, agricultura e obras.

A categoria participação social integrou as ocorrências associadas à participação dos diferentes atores sociais parceiros do programa, as comunidades e ações coletivas. A categoria seguinte - desenvolvimento sustentável - configura a ideologia que delineia o programa. Foram contabilizados os termos sustentabilidade e sustentável, associados às práticas e técnicas sustentáveis. A sexta categoria - pesquisa - engloba as ações de estímulo e desenvolvimento de projetos de pesquisa, desenvolvimento científico e tecnológico. Essa categoria tem relação direta com o Parque Tecnológico Itaipu (PTI), criado pela empresa e que vem funcionando como alicerce para convênios de educação, pesquisa e extensão com universidades, polos de pesquisa nacionais e internacionais que sejam de interesse do programa $\mathrm{CAB}$. A sétima categoria retrata outra premissa do programa: a gestão de bacias hidrográficas.

Revbea, São Paulo, v.16, № 1: 45-65, 2021. 
Tabela 1: Categorias, termos e número de ocorrências.

\begin{tabular}{|c|c|c|}
\hline Categoria & Termo & $\begin{array}{l}\text { Número de } \\
\text { ocorrências }\end{array}$ \\
\hline \multirow{8}{*}{ 1. Integração social } & Acordo & 3 \\
\hline & Convênios & 7 \\
\hline & Cooperação & 17 \\
\hline & Intercâmbio & 3 \\
\hline & Integração & 7 \\
\hline & Pactos & 4 \\
\hline & Parcerias & 10 \\
\hline & Protocolo de intenções & 2 \\
\hline \multicolumn{2}{|c|}{ Total } & 53 \\
\hline \multirow{5}{*}{ 2. Processos formativos } & Capacitação & 5 \\
\hline & Curso & 6 \\
\hline & Educação & 12 \\
\hline & Educação Ambiental & 27 \\
\hline & Manual & 2 \\
\hline \multicolumn{2}{|c|}{ Total } & 52 \\
\hline \multirow{2}{*}{ 3. Política municipal } & Prefeitos & 12 \\
\hline & Secretários & 3 \\
\hline \multicolumn{2}{|c|}{ Total } & 15 \\
\hline \multirow{3}{*}{ 4. Participação social } & Coletivos & 5 \\
\hline & Comunidades & 27 \\
\hline & Participação & 19 \\
\hline \multicolumn{2}{|c|}{ Total } & 51 \\
\hline \multirow{3}{*}{$\begin{array}{c}\text { 5. Desenvolvimento } \\
\text { sustentável }\end{array}$} & Desenvolvimento sustentável & 7 \\
\hline & Sustentabilidade & 15 \\
\hline & Passivos ambientais & 5 \\
\hline \multicolumn{2}{|c|}{ Total } & 27 \\
\hline \multirow{3}{*}{ 6. Pesquisa } & Desenvolvimento científico & 2 \\
\hline & Desenvolvimento tecnológico & 2 \\
\hline & Pesquisa & 8 \\
\hline \multicolumn{2}{|c|}{ Total } & 12 \\
\hline \multirow{6}{*}{$\begin{array}{l}\text { 7. Gestão de Bacias } \\
\text { Hidrográficas }\end{array}$} & Água & 98 \\
\hline & Recursos Hídricos & 9 \\
\hline & Rios/Córregos & 15 \\
\hline & Bacias & 8 \\
\hline & Microbracias & 19 \\
\hline & Bacia do Paraná 3 & 33 \\
\hline \multicolumn{2}{|c|}{ Total } & 182 \\
\hline
\end{tabular}

Fonte: autoria própria.

Importa resgatar que o programa $\mathrm{CAB}$ configura-se como um programa de gestão territorial e ambiental, alicerçado na gestão participativa e que tem a Educação Ambiental como instrumento de integração dos programas, ações e atores sociais. Nesse sentido, a categoria integração social contou com 53 ocorrências e os termos mais frequentes foram "cooperação" e "parcerias" que remetem às ações de intervenção socioambiental integradas da empresa com as instituições governamentais, privadas, do terceiro setor e comunidades.

Quanto aos processos formativos (52 ocorrências), os termos "educação" e "Educação Ambiental" prevalecem, o que reforça a Educação 
Ambiental como eixo estruturante do $\mathrm{CAB}$ e a interação desse programa com os outros programas do CAB. Além disso, das 31 matérias do jornal, quatro foram destinadas ao PEA, conforme salientado anteriormente. Essas matérias abordaram a EA como cerne do programa, as metodologias utilizadas e deram destaque à participação social, através do monitoramento participativo dos rios.

As categorias pesquisa e política municipal foram as menos frequentes, com 12 e 15 ocorrências respectivamente. A categoria desenvolvimento sustentável teve 27 ocorrências sendo que as práticas e técnicas sustentáveis mereceram maior destaque. Salienta-se que o termo "passivo ambiental" apareceu em cinco momentos das matérias de forma associada às ações da empresa de recuperação, conservação e compensação ambiental. Interessante observar que as categorias integração social, processos formativos e participação social atingiram ocorrências em números bem similares, o que denota um discurso apoiado nos princípios do programa.

Quanto à categoria recursos hídricos, essa preponderou pela ocorrência de diferentes termos acoplados à categoria e também em função da conexão com a matriz de pensamento e ação do programa, ou seja, a gestão da bacia hidrográfica e dos cursos d'água associados ao reservatório da empresa.

Com o objetivo de verticalizar a análise, foram examinados os discursos de duas personalidades que conceberam o programa a partir da identificação de termos-chave: a matéria que abre o jornal, de autoria do então Diretor de Coordenação e Meio Ambiente da empresa, Nelton Miguel Friedrich e do teólogo, filósofo e escritor, Leonardo Boff.

O texto de Friedrich, intitulado Outro mundo é necessário, é marcado por uma visão catastrófica/salvacionista, por argumentos que evocam sentimentos e emoções associados ao sofrimento, pela imputação de responsabilidades a todos de forma igualitária e, ao fim, convoca para a necessidade de mudanças de hábitos e para uma nova cultura de relacionamento entre os seres humanos e destes com a natureza. A visão catastrófica fica refletida no uso de termos e expressões tais como: planeta enfermo, desesperador, deplorável estado de coisas, destruição, esgotamento, extinção massiva, exaustão, degradação, conflitos violentos, inferno na Terra, tudo tende a ficar cada vez pior. A visão salvacionista se expressa no uso das expressões: mudança salvadora, missão salvadora, pagar o preço da salvação.

Quando o autor se refere à responsabilidade pelo cenário planetário, o uso de termos como "ninguém" - "A ninguém é dado fugir do problema, ou jogá-lo às costas dos outros" (FRIEDRICH, 2007, p.2) - ou todos - "Cada ser humano tem que colocar seu tijolo nessa construção. Ou será que governantes, algum país, grandes empresas, instituições renomadas darão um jeito? Evidentemente, eles todos têm papel fundamental, mas igualmente fundamental é o papel de cada pessoa" (FRIEDRICH, 2007, p.2) - nos remete à universalização da responsabilidade pelo problema socioambiental. A 
imputação igualitária de responsabilidades entre cidadãos e empresas, governos, multinacionais acaba por comprometer a coerência do texto, que inicialmente apontava os padrões dominantes de produção e consumo como causadores de devastação ambiental.

Como colocar no mesmo patamar responsabilidades das multinacionais do agronegócio e um cidadão? Como convocar o cidadão para a mudança nos hábitos de vida, sem apontar a necessidade de revisão do modelo de exploração e produção capitalista das empresas e corporações?

Questiona-se, assim, o posicionamento de colocar cidadãos e empresas num mesmo plano de causa e efeito, sem ponderação dos papéis e responsabilidades diferenciadas. Nesse sentido, Rodrigues (2006, p.12) também avalia criticamente esse posicionamento:

As ideias de desenvolvimento sustentável, sustentabilidade, referendam que todos os homens são iguais, (perante a lei) todos tem o direito universal de "viver num ambiente saudável" e sobretudo, todos tem o direito de garantir um "ambiente saudável" para as futuras gerações. Aprimora-se a forma de ocultar os conflitos de classe, as formas de apropriação de riquezas e a importância do território.

Além disso, no texto de Friedrich, podemos perceber uma visão naturalizada e mítica da natureza, como em "exige uma nova cultura de relacionamento entre os seres humanos e destes com a natureza... (FRIEDRICH, 2007, p.2), visão esta que fragmenta a natureza ao dissociar seres humanos e os outros componentes da natureza e que reforça a ruptura entre mundo natural e cultural, ruptura que contraria a visão sistêmica de ambiente e manifestação da vida.

O autor, ao lançar mão de vocábulos de conotação religiosa tais como inferno, missão salvadora, pagar o preço da salvação, faz-nos associar o discurso à pregação, possibilitando conectar o discurso socioambiental à uma catequese para a salvação planetária, apesar da citação de evidências científicas na parte inicial do texto. Em formulação nossa, a mensagem final do texto pode ser resumida como: "Para não irmos para o inferno, é preciso mudar nossos hábitos".

Essa estratégia discursiva está bem ajustada ao perfil da população da BP3, que tem características de grande religiosidade e onde católicos, batistas e protestantes preponderam sobre os espíritas, budistas e ateus. Importa salientar que 0 autor tinha 0 papel de sensibilizar as pessoas para a problemática socioambiental realizando palestras para prefeitos, secretários e lideranças locais no início das atividades do CAB em cada município.

Esse aspecto da religiosidade que permeia o $C A B$ foi abordado na dissertação de mestrado de Silvana Silva (2017, p.86) quando a pesquisadora 
aponta que é possível verificar nas bases conceituais e metodológicas do CAB "[...] traços políticos ideológicos que identificam um referencial baseado em uma teologia cristã de indicação progressista [...]".

A visão catastrófica/salvacionista é profícua no sentido de sensibilizar, tocar o ouvinte pelas emoções e sentimentos. Ao mesmo tempo, acena com a possibilidade de fuga do inferno na Terra, pela ação individual de mudança. Como estratégia inicial de sensibilizar e chamar a atenção das pessoas, de mobilizar o leitor/ouvinte tal como ocorria nas palestras proferidas pelo autor na BP3, o texto cumpre sua função de abrir espaço em seguida para as ações de intervenção socioambiental do $\mathrm{CAB}$ e resultados alcançados que perfazem o escopo do jornal.

Poderíamos pensar em outra abordagem que não tangenciasse o modelo civilizatório baseado no capitalismo e no cidadão consumidor e que interpelasse de forma crítica o leitor: Por que outro mundo é necessário? Outro modelo de mundo é necessário. "Nesse outro modo de dizer, outras palavras seriam mobilizadas produzindo outros efeitos de sentidos" (ORLANDI, 1999, p.29). Essa opção oportunizaria um diálogo menos doutrinador pelo medo e mais dialógico com o leitor possibilitando o cotejo entre as evidências científicas e o papel do cidadão, das empresas e dos governos.

O texto seguinte é de Leonardo Boff, intitulado Entramos no reino da razão cordial, e é destinado ao Arqueólogo do Futuro. O texto resgata a lógica do sofrimento humano, os diversos alertas da comunidade científica e constrói o cenário devastador: "caso isso viesse a ocorrer, representa a inauguração da era das devastações. Se nada fizéssemos até os anos 2030-2040, conheceríamos a tribulação da desolação" (BOFF, 2007, p.3).

Na sequência o autor aponta que:

algo inaudito aconteceu e estava dentro das possibilidades humanas a emergência da cooperação e da razão cordial, mas que, na civilização imperante, marcada pela competição e pela razão instrumental, tinha poucos espaços de realização. Agora, face ao iminente perigo de que não houvesse uma Arca de Noé que salvasse alguns e deixasse perecer os demais e de que todos igualmente poderíamos perecer, verificou-se uma lenta, mas progressiva transformação no estado da consciência humana (BOFF, 2007, p.3).

Interessante observarmos que Boff continua na linha de Friedrich lançando mão de aproximações religiosas - "Arca de Noé", "salvasse" - e universalizando as causas e efeitos - "todos igualmente poderíamos perecer". Mantém a mobilização do outro pelo medo, pelo sofrimento, e a uniformização dos efeitos da ação humana no planeta, desconstruindo a lógica da desigualdade social, da diferenciação do acesso à segurança alimentar, saúde, 
educação, saneamento, por exemplo. Mais uma vez, o texto tangencia o modelo civilizatório baseado no capitalismo e no consumo.

$\mathrm{Na}$ sequência, o autor avança para a descrição da tomada de consciência da humanidade, remete aos movimentos desde a década de 70 voltados à discussão da problemática socioambiental, designa como projeto de Salvação da Vida e da Terra e vai paulatinamente construindo um cenário de propósitos coletivos de regeneração da Terra e de construção do império da ética do cuidado e da compaixão, convocando também as diferentes religiões e tradições espirituais a se colocarem juntas a serviço da vida e dos valores que mais protegem a vida: "assim, todos confiados na salvação da humanidade e da Terra, inauguram o reino da razão cordial' (BOFF, 2007, p.3).

Boff sinaliza para o futuro, de superação das adversidades a partir da revisão dos valores e propõe um imperativo ético nas relações, e dessa forma, apresenta um dos pilares do programa CAB, qual seja, a ética do cuidado alicerçada no repensar dos valores civilizatórios. Em suas palestras na BP3, o autor designava a crise socioambiental como uma crise civilizatória, do modelo de sociedade baseada no capitalismo e no sujeito-consumidor. Em determinado momento do texto, o autor expressa essa visão: "ninguém seria perdulário ou viveria no luxo. O projeto de vida é viver na simplicidade voluntária" (BOFF, 2007, p.3).

Mais uma vez o objetivo dos discursos é de sensibilizar o leitor para a problemática socioambiental, mas servindo-se da visão catastrófica, do medo e de aproximações religiosas, a partir do padrão doutrinador. O uso dos termos "reino", no título, e "império", no decorrer do texto, remetem-nos à desigualdade social, aos modelos de exploração do outro, o que contraria o clamor da ética do cuidado e da razão cordial e "o cuidado de uns para com os outros".

Assim, a alteração do título para Entramos na era da razão cordial, ou Entramos no período da razão cordial não nos faria identificar de forma tão clara o viés da Ideologia do Desenvolvimento Sustentável que permeia ambos os textos e que alimenta as diferenças entre consumidores, a exploração e a subjugação aos padrões massivos de consumo, pois "reino" e "império" preconizam súditos, monarcas e povos subjugados. Por outro lado, "reino" também pode nos remeter ao reino dos céus, mais uma alusão ao contexto religioso que tem conexão íntima com o autor, teólogo, expoente da Teologia da Libertação no Brasil.

Friedrich e Boff foram personagens importantes da concepção do Programa $\mathrm{CAB}$ e atuaram como sensibilizadores e mobilizadores sociais ao longo dos 14 anos de gestão de Friedrich à frente da diretoria de coordenação da Itaipu Binacional.

Como dissemos anteriormente, as alusões religiosas são mobilizadoras para o perfil de pessoas da região abarcada pelo programa, mas essa abordagem é limitante no sentido que mobiliza, mas não leva a uma reflexão mais ampla política e social. De fato, a sensibilização orquestrada por eles 
fazia efeito. A respeitabilidade de ambos, a autoridade político-social, dava a eles audiência e capacidade de mobilizar pessoas para a atuação no programa.

Contudo, tornava acentuado os esforços de reconfiguração conceitual e política das equipes técnicas do programa $C A B$, sobretudo da equipe de Educação Ambiental que era a responsável por trabalhar os princípios e valores do programa e formar educadores ambientais que atuariam como PAPs nas comunidades. Inúmeras vezes, a visão religiosa e pouco alicerçada em evidências científicas afastou pessoas, mas também oportunizou diálogos reflexivos sobre o programa. Apesar da respeitabilidade de ambos os autores, as incoerências entre discurso e ação ficavam claras para os sujeitos mais críticos, e essas inquietudes eram tratadas nos grupos participantes do PEA.

Ressalta-se aqui a importância do processo de sensibilização e mobilização das pessoas para a atuação socioambiental e cidadã, mas sinalizamos que nesse processo a informação científica, a apresentação de modelos de análise de dados e de visões que se contrapõem são importantes para estimular a criticidade, a ampliação da visão de mundo e de capacidade de observação das pessoas e, nesse sentido discursos que se aproximem do dogmatismo, religioso, ou científico, não corroboram para a formação crítica dos educadores ambientais.

\section{Conclusões}

O Programa de Educação Ambiental do $\mathrm{CAB}$, ao longo dos anos, foi se constituindo numa teia de parceiros e educadores ambientais que participavam anualmente do Encontro do Programa Cultivando Água Boa. A estratégia de divulgar o jornal no momento do encontro anual do Cultivando Água Boa era profícua, pois cerca de 4.000 pessoas, anualmente, participavam desse encontro, recebiam os jornais daquele ano e, assim, acessavam informações sobre 0 andamento do programa e se viam inseridas nas matérias, o que implicava no fortalecimento da identidade de um coletivo da BP3. O Jornal do Cultivando Água Boa configurou-se, portanto, como um registro de resultados, ideias e percepções a partir da empresa, oportunizando a manifestação de cientistas, políticos e cidadãos engajados no programa.

A Educação Ambiental representou na análise realizada 12,9\% das 31 matérias que compõem o jornal, $13,6 \%$ das citações entre as categorias temáticas de análise (processos formativos), com percentuais próximos das categorias participação social e integração social. Das imagens constantes no jornal, $44,6 \%$ são de comunidades e parceiros do CAB e $44,6 \%$ de cientistas e técnicos. O envolvimento de figuras públicas associadas à defesa socioambiental tais como Marcos Palmeira e Maria Betânia pode ser avaliada como demonstração de força política e social da empresa.

A continuidade do exercício de análise dos discursos associados aos jornais do CAB poderá aclarar as redes de poder e os papéis e estratégias que deram visibilidade ao programa, bem como identificar as contradições 
discursivas que, por sua vez, podem ter atuado como fatores limitantes à expansão do programa e que são importantes de serem identificados, no sentido de delinearmos recomendações para a reaplicabilidade do CAB em outros territórios, a partir da lógica da educação como eixo norteador de programas de gestão de bacias hidrográficas.

Outro aspecto discursivo a ser melhor explorado é o silenciamento apontado por Amaral (2018) ao analisar o programa de formação de educadores ambientais. De fato, a alusão aos impactos e passivos ambientais da Itaipu Binacional aparece apenas em cinco referências associadas à realocação dos povos indígenas e à recuperação ambiental de matas ciliares e solo no jornal. De forma similar, quanto ao contexto histórico de implantação da hidrelétrica na região da Tríplice Fronteira, apenas uma matéria lhe faz menção e o foco é o encerramento do ciclo da construção da usina, com a implantação das últimas turbinas, fato apontado pelos presidentes Luiz Inácio Lula da Silva do Brasil e Nicanor Duarte Frutos do Paraguai.

Da mesma forma as análises dos textos de Nelton Miguel Friedrich e Leonardo Boff contribuíram para traçar fios condutores de narrativas acerca da problemática ambiental expondo contradições, reforço a ação individual versus responsabilidade coletiva, e mobilizações afetivas voltadas para a sensibilização das comunidades baseadas numa visão catastrófica. É provável que a continuidade da análise dos jornais do CAB aclare outras estratégias discursivas, outras narrativas, alternância de narrativas e formas diferenciadas de abordagem da questão socioambiental.

Temos a convicção íntima de que esse breve ensaio descortinou as possibilidades de aplicabilidade da análise do discurso e do conteúdo para a compreensão das vozes e discursos mobilizados no $C A B$ e como esses discursos corroboraram as narrativas da Educação Ambiental.

\section{Agradecimentos}

Ao Instituto de Geociências da Universidade Federal de Minas Gerais (UFMG), professores e colegas do doutorado, pelo apoio e trocas de ideias fundamentais para o desenvolvimento deste trabalho.

\section{Referências}

AMARAL, A.Q. Educação Ambiental e a dimensão política: um estudo de caso do programa de formação de educadores ambientais da usina hidroelétrica Itaipu Binacional. 2018. 308f. Tese (Doutorado em Educação) - Instituto de Biociências de Rio Claro, Universidade Estadual Paulista. Disponível em: $<$ https://repositorio.utfpr.edu.br/ispui/bitstream/1/4613/1/UNESP PPGE D Am aral\%2CAnelizeQueiroz 2018.pdf>. Acesso em: 10 jan. 2020.

BOFF, L. Entramos no reino da razão cordial. Cultivando Água Boa, Foz do Iguaçu, junho, 2007.

Revbea, São Paulo, v.16, № 1: 45-65, 2021.

revista brasileira

educação ambiental 
CARVALHO, P.G.S.; CASALE, V.C; FURTADO, A.S.P; ALBERTON, L.F. Breve Abordagem Perceptiva dos Participantes do FEA: programa de formação de educadores e educadores ambientais. Revista Educomunicação e Educação Ambiental, Rio de Janeiro, v. 3, n. 2, 2013.

CASALE, V.C.; LINDINO, T.C. A Educação Ambiental Empresarial como Condição Estratégica na Empresa. Curitiba-PR: CRV, 2017.

CASALE, V.C; ALBERTON, L. de F; ROCKER, C. Coletivo Educador da Bacia do Paraná 3. In: FERRARO JUNIOR, L.A. (Org.). Encontros e Caminhos: Formação de Educadoras(es) Ambientais e Coletivos Educadores. v. 3. Brasília: MMA/DEA, 2014.

CULTIVANDO ÁGUA BOA, 2017. Disponível em: $<$ http://www.cultivandoaguaboa.com.br/o-programa/sobre-o-programa $>$. Acesso em: 20 ago. 2017.

DOMínGUEZ, A.G.D.; PIMENTEL, F.B. O Programa Cultivando Água Boa: uma avaliação desde a perspectiva da colonialidade. Revista Eletrônica de Relações Internacionais, Centro Universitário Unieuro, n. 20, 2017.

FRIEDRICH, N.M. Outro mundo é necessário. Cultivando Água Boa, Foz do Iguaçu, junho, 2007.

ITAIPU. Relatório de sustentabilidade da Itaipu Binacional. Foz do Iguaçu: Edição Itaipu Binacional, 2007.

KLUNK, L.; MAZZARINO, J.M.; TURATTI, L. O Educador Ambiental do Projeto Cultivando Água Boa da Bacia Hidrográfica do Paraná III. Revista Brasileira de Educação Ambiental, v. 13, n. 3, 2018.

NATIVA SOCIOAMBIENTAL. Dossiê da Educação Ambiental: relatório interno para Itaipu Binacional. 2015.

ORLANDI, E.P. Análise de discurso: princípios e procedimentos. CampinasSP: Pontes, 1999.

PÊCHEUX, M. Semântica e Discurso: uma crítica a afirmação do óbvio. Tradução de Eni Puccinelli Orlandi et al. Campinas-SP: Unicamp, (1975), 1988.

ROCHA, A.S. As vertentes características e os sistemas pedológicos como instrumentos de análise para a identificação das fragilidades e potencialidades ambientais na Bacia Hidrográfica do Paraná 3. 2016. 165f. Tese (Doutorado em Geografia) - Universidade Estadual de Maringá, PR. Disponível em: <http://repositorio.uem.br:8080/ispui/handle/1/2882>. Acesso em: 24 fev. 2020.

ROCKER, C.; CASALE, V.C.; MARQUES, J.N. Estado da Arte das Comunidades de Aprendizagem do Programa de Formação de Educadores(as) Ambientais (FEA) da Bacia do Paraná 3. XVI Encontro Paranaense de Educação Ambiental (EPEA), 2017, Curitiba. Anais... Curitiba: UFPR, 2017. Disponível em: <http://www.epea2017.ufpr.br/wp-content/uploads/2017/05/382E3-S1-ESTADO-DA-ARTE-DAS-COMUNIDADES.pdf>. Acesso em: 07 fev. 2020. 
RODRIGUES, A.M. Desenvolvimento Sustentável dos conflitos de classes para o conflito de gerações. Panorama da Geografia Brasileira, v. 2, 2006. Disponível em: <http://www.slideshare.net/blogarlete/dessustentavel-doconflito-de-classes-para-o-de-geraes> Acesso em: 07 fev. 2020.

SAUVÉ, L. Uma cartografia das correntes em Educação Ambiental. In: SATO, M.; CARVALHO, I. (Orgs.). Educação Ambiental: pesquisa e desafios. Porto Alegre: Artmed, 2005.

SILVA, S.S. 2017. 149f. Avaliação da implantação e dos resultados do Subprograma Gestão por Bacias. Programa Cultivando Água Boa (Itaipu) na sub-bacia hidrográfica Santa Rosa - Município de Cascavel (PR). Dissertação (Mestrado em Geografia) - Universidade Estadual do Oeste do Paraná, Campus de Marechal Cândido Rondon. Disponível em: $<$ http://tede.unioeste.br/handle/tede/3149>. Acesso em: 21 fev. 2020.

TOZONI-REIS, M.F. de C. Pesquisa ação: compartilhando saberes; pesquisa e ação educativa ambiental. In: FERRARO JÚNIOR, L.A. (Org.). Encontros e caminhos: formação de educadores ambientais e coletivos educadores. v. 1. Brasília: MMA /DEA, 2005.

VIEZZER, M.; PLETSCH, R.; DAHLEM, R.B.; VITORASSI, S.; CASALE, V.C. Círculos de aprendizagem para a sustentabilidade, $1^{\underline{a}}$ ed. Foz do IguaçuPR: Itaipu Binacional; Ministério do Meio Ambiente, 2007.

VITORASSI, S. Construção participativa de indicadores de avaliação do Programa de Educação Ambiental da Itaipu Binacional. 2014. 385f. Tese (Doutorado em Educação Ambiental) - Departamento de Pedagogia Aplicada e Psicologia da Educação, Universitat de les Illes Balears. Disponível em: $<$ https://www.tdx.cat/bitstream/handle/10803/371448/tsv1de1.pdf? sequence=1 > . Acesso em: 20 fev. 2020.

VITORASSI, S; SORRENTINO, M; TROBAT, M.F.O. Programa de Educação Ambiental de Itaipu: avanços e desafios de uma experiência de enraizamento da Educação Ambiental na Bacia Hidrográfica do Paraná 3. Revista Olhar de professor, Ponta Grossa, v. 14, n. 2, 2011. 